\title{
Residual capacity for avoidance learning in decorticate rats: Enhancement of performance and demonstration of latent learning with d-amphetamine treatments
}

\author{
MICHAEL S. BEATTIE, THACKERY S. GRAY, JOHN A. ROSENFIELD, \\ PATRICIA M. MEYER, and DONALD R. MEYER \\ The Ohio State University, Columbus, Ohio 43212
}

\begin{abstract}
Unoperated and decorticated rats were trained on a shuttlebox conditioned avoidance response (CAR) according to a sequential schedule of d-amphetamine sulfate $(1.0 \mathrm{mg} / \mathrm{kg})$ or vehicle injections. Unoperated rats acquired and retained the CAR regardless of drug conditions, with amphetamine tending to increase performance. Amphetamine enhanced locomotor activity in unoperated and operated rats under all conditions. Decorticate rats failed to show evidence of acquisition during initial training whether given amphetamine or vehicle injections. However, amphetamine injections resulted in dramatic increases in CAR performance only in decorticates which had no previous experience with the drug. Return to the vehicle-alone condition was accompanied by returns to low levels of responding. The rapid performance increments and their state-dependent nature suggested not only that rats with neocortical removals could acquire a CAR, but that such animals, trained without drug treatments, can acquire information about the CAR situation which they are unable to employ successfully, and that these "latent" traces can henceforth be expressed under the facilitatory effects of amphetamine.
\end{abstract}

A variety of behaviors which are either lost or impaired following central nervous system (CNS) damage can be reinstated by treatments with amphetamine. Reflex responses such as righting (Macht, 1950; Maling \& Acheson, 1946); locomotion (Macht, 1950), and placing (Amassian, Ross, Wertenbaker, \& Weiner, 1972; Braun, 1966; Macht, 1950; Meyer, Horel, \& Meyer, 1963; Ritchie, Meyer, $\&$ Meyer, 1976) are examples of one class of behaviors that are postoperatively recoverable via pharmacological injections. Other investigators have examined the effects of amphetamine upon acquisition of conditioned avoidance responses (CAR) and have reported that deficits seen following brain damage are significantly reduced by the drug injections (Krieckhaus, 1965). Furthermore, there is evidence that amphetamine injections result in partial sparings of postoperative retention of a black-white discrimination in rats prepared with posterior neodecortications (Braun, Meyer, \& Meyer, 1966; Jonason, Lauber, Robbins, Meyer, \& Meyer, 1970).

Several explanations have been offered for the ability of amphetamine treatments to improve or reinstate behaviors lost following CNS damage. In the case of CAR acquisition studies, the facilitated learning seemed to be related to the locomotor stim-

This research was supported, in part, by Grant MH-06211 from the National Institute of Mental Health to Donald R. Meyer and Patricia M. Meyer. ulant properties of the drug. Thus, increased movement (Cardo, 1960) or decreased freezing and crouching (Krieckhaus, 1965; Krieckhaus, Miller, \& Zimmerman, 1965) could account for the enhanced learning. Such an explanation, however, could not account for the recovery of black-white habits in amphetamine-treated rats with posterior decortications, for the drug facilitated relearning but not initial acquisition of the habit (Braun et al., 1966). These latter data indicated that the deficit following surgery was not a result of the destruction of memorial substrates for the black-white habit, but rather, it appeared to be a consequence of a lesion-induced disruption of the mechanisms subserving retrieval of the habit.

In the present experiment, we trained rats with nearly complete removals of the neocortex on a shuttlebox avoidance problem under alternate treatment periods of saline and d-amphetamine. Since such decorticate preparations cannot acquire a twoway conditioned avoidance task (Meyer, Johnson, \& Vaughn, 1970), we wanted to determine if their performance could be facilitated via pharmacological injections, and if so, to examine the conditions under which reinstatements might occur.

\section{EXPERIMENT 1}

\section{Method}

In Experiment 1, normal animals were tested to ensure that the 
paradigm employed for decorticate rats was one in which unoperated animals would learn and maintain a conditioned avoidance response (CAR).

Subjects. Ten Long-Evans hooded rats, weighing between 350 and $450 \mathrm{~g}$ at the beginning of testing, were employed. The animals were housed in separate cages and were maintained on an ad-lib food and water schedule.

Apparatus. A metal shuttlebox (Lafayette Instruments) with two compartments, each measuring $20 \times 25 \times 30 \mathrm{~cm}$, was used. The compartments were separated by a metal vartition with a $10 \times 10 \mathrm{~cm}$ opening. In each unit were two overhead $15-\mathrm{W}$ incandescent lamps, the light from which was diffused by $.64-\mathrm{cm}$ translucent Plexiglas. One-way-vision glass on one wall of both compartments permitted observation of the animals. The floor was composed of $.48-\mathrm{cm}$ stainless steel grids spaced $1.27 \mathrm{~cm}$ apart. The conditioned stimulus (CS) was a buzzer that was $10 \mathrm{sec}$ in duration and $9 \mathrm{~dB}$ SPL above background noise level; it was mounted $25 \mathrm{~cm}$ above the top-center of the apparatus. The unconditioned stimulus (UCS) was a $0.6-\mathrm{mA}$ ac scrambled footshock provided by a Grason-Stadler model E1046GS shock generator. Avoidance and escape latencies were measured by means of a Lafayette timer. Intertrial intervals (ITIs) and the CS-UCS interval were programmed with conventional electromechanical equipment.

Adaptation and Training procedures. On Day 1 of adaptation, each rat was allowed to move freely about the shuttlebox for $10 \mathrm{~min}$, and the number of crossings between compartments were recorded. On Day 2 of adaptation, the animals were given $\mathbf{3 0}$ 10-sec presentations of the CS with ITIs of 15 and $30 \mathrm{sec}$ varied quasirandomly. The number of crossings to the CS and during the ITIs were recorded. If the rat exhibited five or more crossings during the CS-on periods, this phase of adaptation was repeated on the following day, and on each subsequent day until an adaptation criterion of five or fewer crossings to the CS during a single session was met. Animals that did not meet this criterion were administered a maximum of seven CS presentation sessions before being moved on to training.

Training commenced on the day following the last adaptation session. Thirty trials were given each day, with ITIs of 40,60 , and $80 \mathrm{sec}$ varied in a quasirandom manner. If after $10 \mathrm{sec}$ of the CS the rat had not crossed to the other compartment, footshock was administered and continued with the CS until the animal escaped by crossing. The latency to avoid or escape was recorded for each trial. Escape latencies of $\mathbf{4 5} \mathrm{sec}$ or longer were scored as "no response," and if an animal consistently failed to escape, shock intensity was increased on subsequent trials until escape responses were exhibited. One animal in Group D-SAS was suffering from an intractable urinary tract infection and failed for 5 consecutive days to make a single escape response. Consequently, he was dropped from the study. Intertrial crossings (IC) were recorded and punished by shock which continued until the animal had returned to the original compartment.

Thirty minutes prior to each training session, each animal received either an injection of $1.0 \mathrm{mg} / \mathrm{kg} \mathrm{d}$-amphetamine sulfate (salt weight) or normal saline. Injections were given intraperitoneally in volumes of $1.0 \mathrm{ml} / \mathrm{kg}$. This dosage was used because pilot data and previous work in this laboratory (Braun et al., 1966) had indicated that $1.0 \mathrm{mg} / \mathrm{kg}$ d-amphetamine could be effective in promoting the recovery of behaviors lost following cortical lesions without producing visible sympathometic symptoms or obvious stereotyped responses. Animals were injected with the saline vehicle on each day of adaptation.

Rats in Groups N-ASA and N-SAS were trained for 30 days following adaptation, with rest days between the 10th and 11th and between the 20th and 21 st training sessions. The sequence of drug treatments during training periods is presented in Table 1.

In addition to the CAR responses, observation of the animals' postural responses to the CS prior to UCS onset (during the interstimulus interval, ISI) were categorized and recorded. If at any time during the ISI the rat exhibited locomotor activity which changed its location within the compartment, a locomotor response was recorded (L). Lifting of the forelegs or maintenance of a bipedal posture was scored as rearing (R). If the animal remained motionless with three or four feet in continuous contact with the grid floor throughout the 10 -sec ISI, a freezing response was recorded (F). The latter category was not meant to exclude the rapid startle responses sometimes observed at the onset of the buzzer which may have in some cases produced a momentary loss of contact with the floor of the compartment.

\section{Results}

Adaptation. Rats in Groups N-ASA and N-SAS were treated identically during the adaptation phase of the experiment, and, since there were no apparent differences between groups, adaptation scores were pooled. These animals exhibited a mean of 19.0 (Mdn = 21) spontaneous crossings during the 10-min period on Day 1 of adaptation. On Day 2, during CS presentations, the animals exhibited a mean of 5.5 $(\mathrm{Mdn}=5.5)$ compartment crossings during interstimulus intervals. Rats in Experiment 1 required a mean of 1.5 days $(\mathrm{Mdn}=1.5)$ to reach the adaptation criterion of five or less crossings during CS presentation.

CAR performance. Figure 1 shows the median number of CARs per 30-trial sessions over the 30 days of training for both groups of unoperated animals. Both groups acquired the CAR fairly rapidly during Days 1-10 of training, with those receiving amphetamine (N-ASA) tending to reach higher levels of correct responding. Training during Days 11-20 constituted a reversal of drug conditions for both groups. Animals in Group N-SAS (now under amphetamine treatment) continued to exhibit high levels of performance. In contrast, each of the rats in Group N-ASA showed an immediate decline in performance under saline conditions. Within a few days, however, performance returned to levels comparable to the levels exhibited during the initial amphetamine phase. Training during Days 21-30 constituted a return

Table 1

Treatment Sequence for Experiments 1 and 2

\begin{tabular}{|c|c|c|c|c|c|}
\hline \multirow[b]{2}{*}{ Group } & \multirow[b]{2}{*}{$\mathrm{n}$} & \multirow[b]{2}{*}{ Adaptation } & \multicolumn{3}{|c|}{ CAR Training } \\
\hline & & & $\begin{array}{l}\text { Phase } 1 \\
\text { Days 1-10 }\end{array}$ & $\begin{array}{c}\text { Phase } 2 \\
\text { Days 11-20 }\end{array}$ & $\begin{array}{c}\text { Phase } 3 \\
\text { Days 21-30 }\end{array}$ \\
\hline $\begin{array}{l}\text { N-ASA } \\
\text { N-SAS }\end{array}$ & $\begin{array}{l}5 \\
5\end{array}$ & $\begin{array}{l}\text { saline } \\
\text { saline }\end{array}$ & $\begin{array}{l}\text { amphetamine } \\
\text { saline }\end{array}$ & $\begin{array}{l}\text { saline } \\
\text { amphetamine }\end{array}$ & $\begin{array}{l}\text { amphetamine } \\
\text { saline }\end{array}$ \\
\hline
\end{tabular}



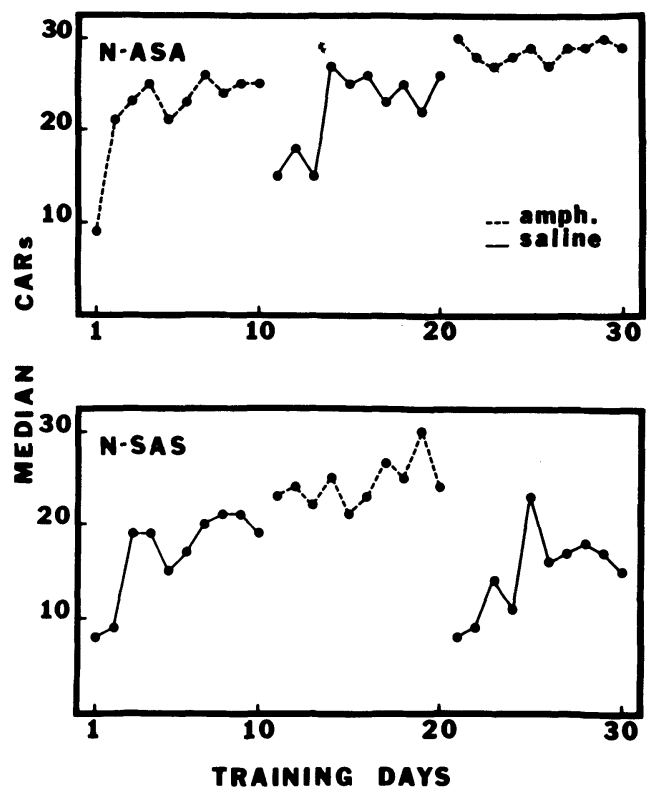

Figure 1. Median CARs for Groups N-ASA and N-SAS.

to original drug conditions for each group. All five of the animals in Group N-SAS exhibited declines in performance when shifted from amphetamine to saline. On the other hand, subjects in Group N-ASA tended to respond more effectively when shifted to amphetamine.

Measures of locomotor responsiveness. Table 2 summarizes the escape and avoidance latency data for Groups N-ASA and N-SAS. Within-groups analyses showed that avoidance latencies differed across the three treatment conditions for each group (Friedman analysis of variance by ranks: N-ASA, $\chi_{\mathrm{r}}^{2}=8.4$, $\mathrm{p}=.0085$; N-SAS, $\left.\chi_{\mathrm{r}}^{2}=10.0, \mathrm{p}=.00077\right)$. All of the five rats in Group N-ASA exhibited longer latencies to avoid under saline conditions than during either of the amphetamine training phases. All of the N-SAS animals avoided most rapidly during Phase 2 training under amphetamine, and displayed their highest avoidance latencies while under saline in the final phase of training. There was no consistent pattern of escape latencies for either of the two groups.

Table 3 presents the mean and median number of intertrial crossings (ITCs) made by each group per 10-day training phase. The number of crossings made by Group N-ASA differed across training phases $\left(\chi_{\mathrm{r}}^{2}=8.4, \mathrm{p}=.0085\right)$, with all five animals making the least crossings during Days 11-20 under saline and four of five exhibiting fewer crossings during the final phase of amphetamine training than during the initial phase of training under the drug. The pattern was not as consistent for the N-SAS subjects, but four of the five animals made more crossings under amphetamine during Phase 2 than during the final saline phase of testing.

Table 4 provides a summary of the mean and median probabilities of locomotor responses made during the ISI when the animals failed to avoid. For both groups, the probability of locomotor (L) responses on nonavoidance trials was greater during training under drug conditions than under saline conditions. Freezing in response to the CS concurrently declined with amphetamine administration, while rearing responses (R) were relatively stable under all conditions.

\section{EXPERIMENT 2}

\section{Method}

Subjects. Twenty-three Long-Evans hooded rats were the subjects in Experiment 2, and were divided into two treatment groups:

Table 2

Mean Escape and Avoidance Latencies for Unoperated Rats in Experiment 1

\begin{tabular}{lrlrrr}
\hline & & & \multicolumn{3}{c}{ Phase } \\
\cline { 4 - 6 } Group & $\mathrm{n}$ & Latency & \multicolumn{1}{c}{1} & \multicolumn{1}{c}{2} & \multicolumn{1}{c}{3} \\
\hline \multirow{2}{*}{ N-ASA } & \multirow{2}{*}{5} & Escape & 10.90 & 11.66 & 10.78 \\
& & Avoidance & 3.08 & 5.03 & 2.63 \\
N-SAS & \multirow{2}{*}{5} & Escape & 11.32 & 11.05 & 11.28 \\
& & Avoidance & 5.51 & 2.98 & 6.47 \\
\hline
\end{tabular}

Table 3

ITCs per Training Phase for Groups N-ASA and N-SAS

\begin{tabular}{|c|c|c|c|c|c|c|c|}
\hline \multirow[b]{2}{*}{ Group } & \multirow[b]{2}{*}{ n } & \multicolumn{2}{|c|}{ Phase 1} & \multicolumn{2}{|c|}{ Phase 2} & \multicolumn{2}{|c|}{ Phase 3} \\
\hline & & Mean & Median & Mean & Median & Mean & Median \\
\hline $\begin{array}{l}\mathrm{N}-\mathrm{ASA} \\
\mathrm{N}-\mathrm{SAS}\end{array}$ & $\begin{array}{l}5 \\
5\end{array}$ & $\begin{array}{l}62.9 \\
42.2\end{array}$ & $\begin{array}{l}69.0 \\
13.0\end{array}$ & $\begin{array}{l}15.6 \\
21.4\end{array}$ & $\begin{array}{r}7.0 \\
14.0\end{array}$ & $\begin{array}{l}44.0 \\
11.0\end{array}$ & $\begin{array}{r}22.0 \\
7.0\end{array}$ \\
\hline
\end{tabular}

Table 4

Mean and Median Probabilities of Responses During ISIs on Nonavoidance Trials for Unoperated Rats

\begin{tabular}{|c|c|c|c|c|c|c|c|c|}
\hline \multirow[b]{2}{*}{ Group } & \multirow[b]{2}{*}{$\mathrm{n}$} & \multirow[b]{2}{*}{ Response } & \multicolumn{2}{|c|}{ Phase 1} & \multicolumn{2}{|c|}{ Phase 2} & \multicolumn{2}{|c|}{ Phase 3} \\
\hline & & & Mean & Median & Mean & Median & Mean & Median \\
\hline N-ASA & 5 & $\begin{array}{l}\mathrm{L} \\
\mathbf{R} \\
\mathrm{F}\end{array}$ & $\begin{array}{l}.619 \\
.115 \\
.304\end{array}$ & $\begin{array}{l}.600 \\
.067 \\
.333\end{array}$ & $\begin{array}{l}.455 \\
.043 \\
.502\end{array}$ & $\begin{array}{l}.522 \\
.000 \\
.478\end{array}$ & $\begin{array}{l}.700 \\
.008 \\
.292\end{array}$ & $\begin{array}{l}.680 \\
.000 \\
.320\end{array}$ \\
\hline N-SAS & 5 & $\begin{array}{l}\mathrm{L} \\
\mathrm{R} \\
\mathrm{F}\end{array}$ & $\begin{array}{l}.440 \\
.038 \\
.522\end{array}$ & $\begin{array}{l}.501 \\
.047 \\
.470\end{array}$ & $\begin{array}{l}.865 \\
.027 \\
.070\end{array}$ & $\begin{array}{l}.876 \\
.012 \\
.000\end{array}$ & $\begin{array}{l}.469 \\
.017 \\
.513\end{array}$ & $\begin{array}{l}.586 \\
.005 \\
.413\end{array}$ \\
\hline
\end{tabular}


D-ASA $(n=12)$ and D-SAS $(n=11)$. Adaptation and training procedures were identical to those in Experiment 1, but in Experiment 2 rats were prepared with large ablations of the neocortex 21 days prior to the onset of testing. Table 1 presents the sequence of testing for each group.

Surgery. All surgeries were performed while the rats were under anesthesia induced by sodium pentobarbital $(65 \mathrm{mg} / \mathrm{kg}$, IP). Both atropine sulfate and an antibiotic were routinely administered. The entire neocortex was ablated via pia stripping and circumferential aspiration according to the method described by Meyer and Meyer (1971).

Histology. Following completion of training, the animals were injected with a lethal dose of sodium pentobarbital and were perfused intracardially with $0.9 \%$ saline solution followed by $10 \%$ Formalin. The brains were removed and the extent of cortical damage was plotted on Lashley diagrams. Each brain was then embedded in celloidin per the procedure of Lauber (1970) and coronal sections were cut at $25 \mu \mathrm{m}$. Every 10th section through the neocortex and every fifth section through the dorsal thalamus were mounted and stained with cresyl violet. In some cases, additional sections were mounted and stained with Luxol-fast blue. The processed sections were carefully examined to determine the degree of retrograde degeneration in the dorsal thalamus. Potential damage to subcortical structures was also assessed. Sections were also compared to the Lashley diagrams with respect to the accuracy of the diagrams in indicating the extent of cortical removal.

\section{Results}

Histology. The lesions of the neodecorticated animals, which are presented in Figure 2, were comparable in size to those in the Meyer et al. (1970) study. The extent of the cortical damage was measured from the surface diagrams by polar planimeter readings, and a Mann-Whitney $U$ test revealed no significant differences in size of lesion between the two surgical groups. Spearman rank correlation coefficients were also calculated to determine the relationship between lesion

\section{LESION EXTENT}

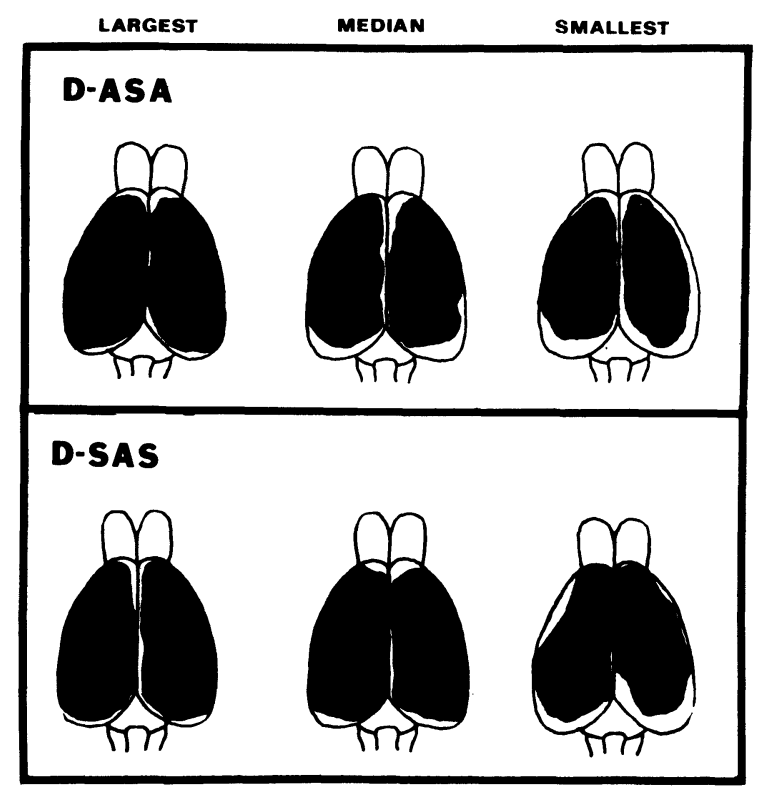

Figure 2. Representative cortical lesions for Groups D-ASA and D-SAS.

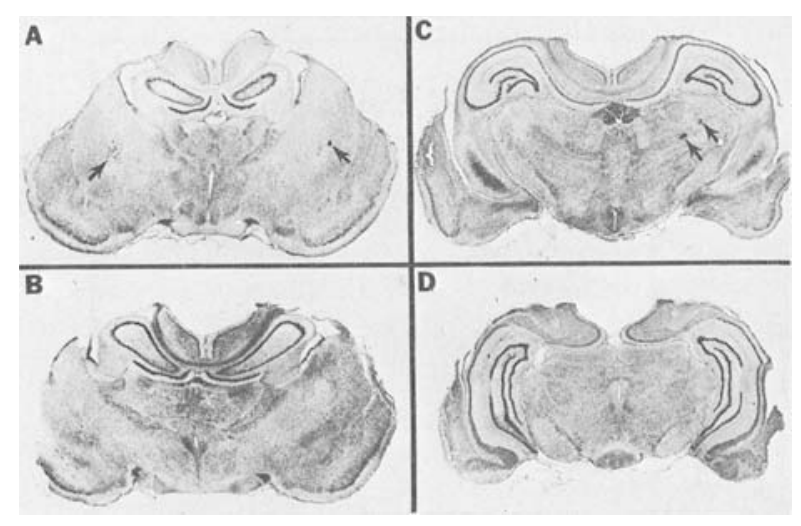

Figure 3. Photomicrographic series of coronal sections indicating the typical amount of dorsal thalamic retrograde degeneration.

size and each of the dependent measures in the study. The results revealed a positive relationship only between lesion extent and the number of crossings made during the initial $10 \mathrm{~min}$ of free exploration on Day 1 of adaptation $\left(\mathrm{r}_{\mathrm{s}}=+.605 ; \mathrm{p}<.01\right)$.

Examination of the dorsal thalamus in the two lesioned groups revealed massive retrograde degeneration, the extent of which corresponded roughly to the extent of the neocortical damage. When sparing of normal cells did occur, it was most often noted in the dorsolateral position of the dorsal lateral geniculate nuclei, the medial geniculate body, and portions of the anterior thalamic nuclei. Figure 3 is a series of photomicrographs of Nissl-stained sections which illustrate the typical degree of thalamic gliosis and cell loss as a result of cortical ablation. Also shown in this figure is a region of necrotic tissue (arrows), which was commonly observed in our material, and which recently has been described by Braun (1975). Braun attributes this debris to incidental vascular damage incurred during the decortication procedure. Typically, it extends throughout the rostral-caudal extent of the thalamus and in the same relative position into the caudate nucleus.

Subcortical damage was minimal, involving only slight anterior or lateral invasions of the caudate in some animals. One subject sustained a partial unilateral transection of the alveous.

Activity during adaptation. Table 5 presents adaptation scores for the two groups included in Experiment 2. Both groups displayed relatively high levels of activity during adaptation, requiring a mean of 4.6 and 3.6 days to reach adaptation criterion. No significant differences were found between the two groups on any of the adaptation scores.

CAR performance. The median number of CARs per day exhibited over 30 days of testing the decorticate rats treated with amphetamine-salineamphetamine (D-ASA) or saline-amphetamine-saline (D-SAS) is illustrated in Figure 4. 
Table 5

Adaptation Scores for Decorticated Rats

\begin{tabular}{|c|c|c|c|c|c|c|c|c|c|}
\hline \multirow[b]{2}{*}{ Group } & \multirow[b]{2}{*}{$\mathrm{n}$} & \multicolumn{2}{|c|}{ First 10 Min } & \multicolumn{2}{|c|}{ To CS, Day 2} & \multicolumn{2}{|c|}{ ITI, Day 2} & \multicolumn{2}{|c|}{ Adaptation Days } \\
\hline & & Mean & Median & Mean & Median & Mean & Median & Mean & Median \\
\hline D-ASA & 12 & 26.8 & 27.0 & 14.3 & 14.0 & 17.5 & 17.0 & 4.6 & 3.5 \\
\hline D-SAS & 11 & 27.9 & 24.5 & 11.4 & 11.5 & 18.0 & 18.0 & 1.5 & 1.5 \\
\hline
\end{tabular}

As expected from the findings of Meyer et al. (1970), decorticate rats which received saline injections during Phase 1 of training performed very poorly, failing to show any evidence of acquisition of the CAR. The decorticate animals which were given amphetamine during the initial phase also performed poorly. Although the subjects in the latter group seemed to be learning the CAR during the first few days of training, their performance tended to decline subsequently, and they failed to demonstrate an increase in daily responding over the 10 days of training in Phase 1. The overall performances of Groups D-ASA and D-SAS were not statistically different, and hence the treatments with amphetamine appeared to have had little or no effect upon the process of acquisition of the habit.

The reversal of drug conditions in Phase 2 of training, however, resulted in dramatic changes in performance. The animals in Group D-SAS showed rapid increases in responding when shifted from saline to amphetamine. This performance increment was evident on the first day of training under amphetamine (number of CARs, Day 10 vs. Day 11: Willcoxin $\mathrm{T}=5.5, \mathrm{p}<.05$ ), and performance continued to increase over the course of Phase 2
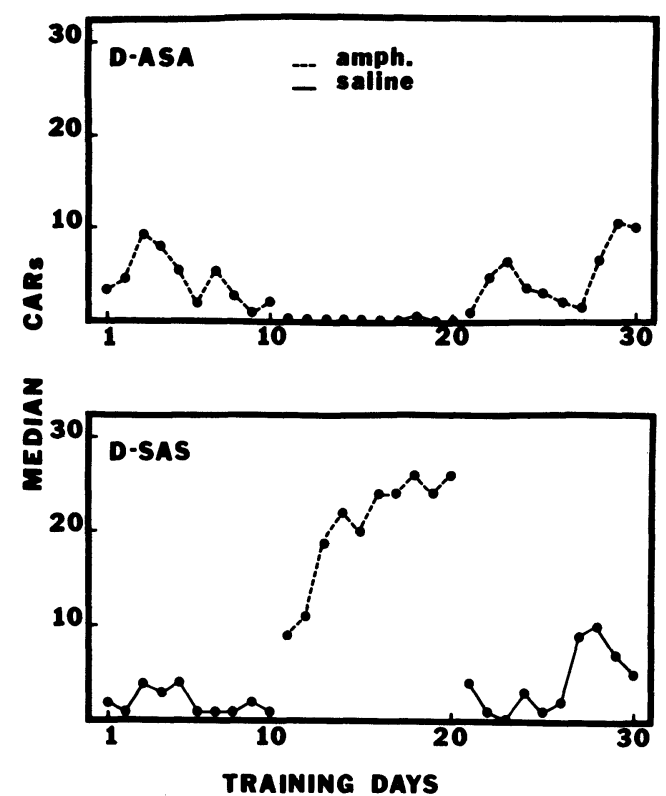

Figure 4. Median CARs for Groups D-ASA and D-SAS. training (Day 11 vs. Day 20 CARs: $T=0, p<.01$ ).

The low levels of responding exhibited by rats in Group D-ASA during Phase 1 declined even further during training under saline in Phase 2. These animals made fewer CARs during Phase 2 than during Phase 1 of training $(T=9, p<.05)$, and even showed a significant decrease in performance from the low levels exhibited on the last day of Phase 1 on the first day of training under saline (Day 10 vs. Day 11 CARs: $T=4, p<.05$ ). Over half of the rats in Group D-ASA failed to make more than two CARs during the entire 10-day training phase. Their performance was dramatically inferior to the D-SAS rats receiving amphetamine during Phase 2 (total CARs, Phase 2, D-SAS vs. D-ASA: MannWhitney U test, $U=195, \mathrm{p}<.02)$.

The decorticate rats in Group D-SAS, which had been performing at high levels under amphetamine, showed an immediate and precipitous decline in performance when shifted to saline conditions in Phase 3 (Day 20 vs. Day 21 CARs, $T=0, p<.01$ ). They also failed to show a significant increase in performance over the final 10 days of training. While their overall performance in Phase 3 was clearly inferior to that in Phase 2 under amphetamine $(\mathrm{T}=0, \mathrm{p}<.01$ ), D-SAS rats did make more CARs during Phase 3 than during their initial training under saline in Phase 1 , which suggested that these animals had benefited either from the 600 trials of training prior to Phase 3 or from some carryover of the facilitatory effects of amphetamine from Phase 2.

When D-ASA rats were shifted from saline to amphetamine conditions at the start of Phase 3, their CAR performance was enhanced, but as in Phase 1, they once again failed to exhibit a reliable improvement in performance over the 10 days of training in the final phase. Also, as in Phase 1, a betweengroups comparison failed to demonstrate a difference in overall performance between the decorticate subjects which received saline or amphetamine during Phase 3. Further, the D-ASA animals did not perform better under amphetamine during Phase 3 than during Phase 1, although it appeared as if during Phase 3 some slight improvement over the course of the training phase might have occurred. And finally, while between-groups comparisons did not reveal a reliable difference between the overall Phase 2 performance of D-SAS rats under amphet- 
amine and the overall performance of D-ASA rats under amphetamine in Phase 3, D-ASA rats never reached the high levels of performance exhibited by D-SAS animals at the end of Phase 2 of training (number of CARs for D-SAS on last day of Phase 2 vs. CARs for D-ASA on last day of Phase 3: $U=30.5, p<.05)$.

Measures of locomotor responsiveness. Table 6 summarizes the escape and avoidance latency data for Groups D-ASA and D-SAS. D-SAS animals exhibited their highest latencies, both to escape and to avoid, during initial training under saline in Phase 1, with no apparent differences between the two subsequent training phases. D-ASA rats took longer to escape shock during Phase 2 training under saline than during either of the amphetamine training phases.

During Phase 1 of training, D-ASA rats escaped shock faster than did rats in Group D-SAS ( $U=$ $30.5, \mathrm{p}<.05$ ), but the robust differences in CAR performance between the two groups in Phase 2 were not reflected in differences in either escape or avoidance latencies. Thus, while amphetamine tended to decrease latencies during initial training, another important factor in determining latencies seems to have been prior experience in the shuttle-avoidance situation.

Table 7 presents the mean and median number of ITCs made by each group of decorticate rats for each of the three phases of training. Within-groups analysis of the number of ITCs per phase revealed significant differences across phases for both groups (Friedman ANOVA: D-ASA, $\chi_{\mathrm{r}}^{2}=17.17, \mathrm{p}<.001$; D-SAS, $\left.\chi_{\mathrm{r}}^{2}=7.67, \mathrm{p}<.05\right)$. D-ASA rats made more ITCs during Phase 1 under amphetamine than during either of the two subsequent phases of training, and made the fewest ITCs during Phase 3 training under saline (Phase 1 vs. Phase 2: $T=0$, $\mathrm{p}<.01$; Phase 2 vs. Phase 3: $\mathrm{T}=0, \mathrm{p}<.01$, Phase 1 vs. Phase 3: $T=11, p<.05$ ). D-SAS animals made fewer ITCs during Phase 3 training under saline than during either of the two phases of training under amphetamine (Phase 1 vs. Phase 2: $\mathrm{T}=3.5, \mathrm{p}<.02$; Phase 1 vs. Phase 3: $\mathrm{T}=1$, $\mathrm{p}<.01)$.

Table 6

Escape and Avoidance Latencies (Mean) for Decorticated Rats

\begin{tabular}{lllccc}
\hline & & & \multicolumn{3}{c}{ Phase } \\
\cline { 4 - 6 } Group & $\mathrm{n}$ & Latency & 1 & 2 & 3 \\
\hline \multirow{2}{*}{ D-ASA } & \multirow{2}{*}{12} & Escape & $14.34^{*} \dagger$ & 16.82 & $13.91^{*}$ \\
& & Avoidance & 3.08 & 5.03 & 2.63 \\
D-SAS & \multirow{2}{*}{11} & Escape & 18.04 & $14.37^{* *}$ & $15.17^{* *}$ \\
& & Avoidance & 5.09 & $3.60^{* * *}$ & $4.29 * * *$ \\
\hline
\end{tabular}

*Significantly different from Phase 2, $p<.05$, Wilcoxon test. **Different from Phase $1, p<.01$, Wilcoxon test. ***Different from Phase $1, p<.02$, Wilcoxon test. tSignificantly lower than for Phase 1, Group D-SAS, $p<.05$, Mann-Whitney $U$ test.
Table 7

ITCs per Phase of Training for Decorticated Rats

\begin{tabular}{|c|c|c|c|c|c|c|c|}
\hline \multirow[b]{2}{*}{ Group } & \multirow[b]{2}{*}{$\mathbf{n}$} & \multicolumn{2}{|c|}{ Phase 1} & \multicolumn{2}{|c|}{ Phase 2} & \multicolumn{2}{|c|}{ Phase 3} \\
\hline & & Mean & Median & Mean & Median & Mean & Median \\
\hline $\begin{array}{l}\text { D-ASA } \\
\text { D-SAS }\end{array}$ & $\begin{array}{l}12 \\
11\end{array}$ & $\begin{array}{l}32.5 \\
13.9\end{array}$ & $\begin{array}{c}21.5 \\
8\end{array}$ & $\begin{array}{r}2.7 \\
22.3\end{array}$ & $\begin{array}{r}2 \\
14\end{array}$ & $\begin{array}{r}21.9 \\
6.1\end{array}$ & $\begin{array}{c}13.5 \\
1\end{array}$ \\
\hline
\end{tabular}

Comparisons between the groups showed that D-SAS rats made more ITCs during training under saline in Phase 1 than did D-ASA rats during training under saline in Phase $2(U=15.5$, $\mathrm{p}<.002)$. Thus, both drug conditions and experience in the avoidance situation seemed to be factors influencing the number of ITCs.

Table 8 shows the mean and median proportions $L, R$, and $F$ responses during the ISI on nonavoidance trials for Groups D-ASA and D-SAS. As for the unoperated rats in Experiment 1, the proportion of $L$ responses varied as a function of treatment condition (Friedman ANOVA: D-ASA, $\chi_{\mathrm{r}}^{2}=12.5$, $\mathrm{p}<.01$; D-SAS, $\left.\chi_{\mathrm{r}}^{2}=8.91, \mathrm{p}<.02\right)$, with D-ASA rats exhibiting the highest proportions of $L$ responses during amphetamine treatment in Phases 1 and 3 (Phase 1 vs. Phase 2: $T=8, p<.05$; Phase 3 vs. Phase 2: $T=10, p<.05$ ) and D-SAS animals showing greater locomotor tendencies during Phase 2 (Phase 2 vs. Phase 1: $\mathrm{T}=8, \mathrm{p}<.05$; Phase 2 vs. Phase 3, $T=10, p<.05)$. The increased locomotor responsiveness seen with amphetamine treatment was coincidental with decreased freezing, while rearing was relatively unaffected by drug treatments.

Further, the proportion of $\mathrm{L}$ responses on nonavoidance trials was closely associated with CAR performance. The CAR performance of individual animals over the entire course of training, as well as over the course of individual phases of training was highly correlated with individual animals' locomotor response tendencies on nonavoidance trials. Spearman rank-order correlation coefficients obtained for the relationship between CAR and $L$ responses within training phases for each of the groups in Experiment 2 ranged from +.832 to +.982 .

Thus, each of the measures of locomotor responsiveness employed in the present study (escape and avoidance latencies, ITCs, and responsiveness to the CS on nonavoidance trials) was sensitive to the effects of amphetamine. However, only responsiveness to the CS on nonavoidance trials was closely related to CAR performance.

\section{DISCUSSION}

The results of the present study confirm an earlier finding (Meyer et al., 1970) that near-total ablations of the isocortex in rats produce a severe deficit in the acquisition and performance of a shuttle-avoidance habit. The data further demonstrate 
Table 8

Mean and Median Proportions of $L$, R, and F Responses During the ISI on Nonavoidance Trials for Decorticated Rats

\begin{tabular}{|c|c|c|c|c|c|c|c|c|}
\hline \multirow[b]{2}{*}{ Group } & \multirow[b]{2}{*}{$\mathbf{n}$} & \multirow[b]{2}{*}{ Response } & \multicolumn{2}{|c|}{ Phase 1} & \multicolumn{2}{|c|}{ Phase 2} & \multicolumn{2}{|c|}{ Phase 3} \\
\hline & & & Mean & Median & Mean & Median & Mean & Median \\
\hline D-ASA & 12 & $\begin{array}{l}\mathbf{L} \\
\mathbf{R} \\
\mathbf{F}\end{array}$ & $\begin{array}{l}.344 \\
.187 \\
.571\end{array}$ & $\begin{array}{l}.290 \\
.063 \\
.595\end{array}$ & $\begin{array}{l}.174 \\
.186 \\
.640\end{array}$ & $\begin{array}{l}.028 \\
.092 \\
.820\end{array}$ & $\begin{array}{l}.396 \\
.155 \\
.435\end{array}$ & $\begin{array}{l}.229 \\
.096 \\
.535\end{array}$ \\
\hline D-SAS & 11 & $\begin{array}{l}\mathbf{L} \\
\mathbf{R} \\
\mathbf{F}\end{array}$ & $\begin{array}{l}.244 \\
.187 \\
.571\end{array}$ & $\begin{array}{l}.061 \\
.063 \\
.595\end{array}$ & $\begin{array}{l}.471 \\
.220 \\
.314\end{array}$ & $\begin{array}{l}.624 \\
.241 \\
.416\end{array}$ & $\begin{array}{l}.285 \\
.166 \\
.577\end{array}$ & $\begin{array}{l}.193 \\
.167 \\
.619\end{array}$ \\
\hline
\end{tabular}

that under certain conditions, the CAR deficit can be reversed by injections of d-amphetamine. At the $1.0-\mathrm{mg} / \mathrm{kg}$ dose employed here, the CAR performances of decorticate rats were greatly enhanced by amphetamine, but only if the animals had received their initial experiences in the training situation without the drug. Operated rats receiving injections of amphetamine during initial training exhibited higher levels of performance than during subsequent training without drug treatments, but failed to show evidence of the kind of acquisition and performance seen in operated controls and in decorticate animals with previous training under saline.

Amphetamine facilitation of responding was highly state-dependent, with returns to saline training conditions being accompanied by significant declines in CAR performance. Thus, the state-dependent facilitation of CAR performance by amphetamine reported previously for intact animals (Barrett, Leith, \& Ray, 1972; Leith \& Barrett, 1975; Rech, 1966; Krieckhaus et al., 1965) was confirmed for the conditions of the present study and extended to the facilitation of CAR performance in rats with extensive ablation of the isocortex. This state dependency points to an important distinction between learning and performance which has received relatively little attention in studies of the residual capacities of brain-damaged preparations.

Numerous investigations have documented the facilitory effects of amphetamine on locomotor behaviors and arousal [see Groves \& Rebec (1976) and Iversen \& Iversen (1975) for reviews], and in the present study, amphetamine tended to increase locomotor responsivenes in both unoperated and decorticate preparations. However, nonspecific druginduced changes in activity and arousal can only partially account for the effects of amphetamine upon the CAR performances of the two groups of decorticate animals. Rats in Group D-ASA showed transient, modest levels of CAR performance when trained under amphetamine in Phase 1 , a decrease in performance when shifted to saline conditions in Phase 2, and a return to modest, but unspectacular, CAR performance levels during amphetamine training in Phase 3. These drug-related changes in performance within Group D-ASA were associated with concomitant increases in measures of locomotor activity, but most particularly in terms of locomotor responsiveness to the CS. The close association between CAR performance and locomotor responsiveness to the CS on nonavoidance trials implies that these two classes of responses both represent subcategories of acquired responses rather than the general activating effects of amphetamine. Our other response measures may be more related to the effects of this drug on general arousal levels, but these measures failed to correlate highly with the appearance of high levels of CAR performance. It might also be noted in this context that the high levels of general locomotor activity exhibited by the decorticate groups during adaptation, prior to the onset of CS-UCS pairings, failed to benefit these animals during subsequent training in the shuttlebox.

On the other hand, the pattern of responding exhibited by D-ASA rats under amphetamine, particularly during Phase 1 , is reminiscent of the performance of rats under pseudoconditioning procedures in the shuttlebox (Izquierdo, 1975). Under such conditions, animals show modest levels of performance initially, but then performance declines, as was the case for D-ASA rats in the present study. Izquierdo (1975) has shown that pseudoconditioned responding in the shuttlebox is increased by LSD, a drug thought to influence processes underlying orienting and locomotor reactivity (Iversen \& Iversen, 1975). Thus, it seems possible that the within-group changes in CAR performance seen in the D-ASA rats in the present study were indeed reflective of drug-induced changes in arousal and activity rather than of changes in the learning ability of these animals.

Such considerations cannot account, however, for the dramatic increases in performance seen for Group D-SAS animals when given amphetamine during Phase 2 . The rapidity with which these animals demonstrated competence in the shuttlebox under amphetamine was comparable to that of normal animals not receiving drug treatments. This, in combination with the relatively poor performance 
of D-ASA animals during initial training under amphetamine, implies that the decorticate rats in Group D-SAS benefited in some way from their experience during Phase 1 , even though that benefit was not at all apparent during the initial training phase. Thus, the amphetamine injections demonstrated the presence of a latent habit, learned during Phase 1 , but not accessible until training under the drug was commenced. This notion gains support from previous work in our laboratory and others which have demonstrated the efficacy of amphetamine in revealing the presence of apparently lost habits and functional capacities in decorticate and other brain-damaged preparations (see Meyer, 1972; Meyer \& Beattie, 1977). Previous work also suggests that amphetamine may be more effective in facilitating the expression of previously acquired habits than in promoting the acquisition of unlearned responses (Beckwith, Sandman, \& Alexander, 1974; Cicala, Ulm, \& Drews, 1971; Hearst \& Whalen, 1963; Meyer, 1972), which may account for the lack of acquisition of the CAR by decorticate rats receiving drug treatments in Phase 1 . Thus, the differential effects of amphetamine upon the CAR performances of the two groups of decorticate rats in the present study might be viewed as reflecting a dissociation between the nonspecific effects of the drug on arousal and activity and the drug's effects upon the retrieval of previously acquired and/or latent associations (see Meyer, 1972; Meyer \& Beattie, 1977).

Given the above considerations, it is difficult to explain why animals in Group D-ASA failed to show dramatic performance increases during Phase 3 training under amphetamine conditions, since the 300 training trials administered under saline during Phase 2 might be expected to provide the same benefit accorded to D-SAS rats during Phase 1 training under saline. Initial training under amphetamine seems to have inhibited the formation of a latent habit during subsequent saline training. Unfortunately, even careful analyses of the performance and activity data of individual animals has failed to provide us with a clear explanation of this negative transfer effect, and further research will be required to elucidate the nature and implications of this phenomenon.

Irrespective of the genesis of the differences in amphetamine's ability to reinstate CAR performance in our two groups of decorticated animals, we think our results have some important implications for analyses of the residual behavioral capacities of preparations subjected to experimental CNS traumas. The dramatic recovery of responding by D-SAS animals demonstrated unequivocally that extensive destruction of the neocortex does not result in the destruction of the neural mechanisms necessary for the performance of a CAR habit. This corroborates a similar conclusion reached by Meyer et al. (1970), who observed that septal lesions can ameliorate the CAR deficits imparted by cortical destructions. Further, our results emphasize that posttrauma losses of the spontaneous expression of habits should not be interpreted as indicative of losses of memorial substrates, since experimental therapeutic techniques may often reveal that such substrates are indeed intact, but merely lack appropriate means of expression.

\section{REFERENCES}

Amassian, V. E., Ross, R., Wertenbaker, C., \& Weiner, H. Cerebellothalamocortical interrelations in contact placing and other movements in rats. In T. L. Frigyesi, E. Rinvik, \& M. D. Yahr (Eds.), Corticothalamal projections and sensorimotor activities. New York: Raven Press, 1972.

Barrett, R. J., Leirt, N. J., \& RAY, O. S. Permanent facilitation of avoidance behavior by d-amphetamine and scopolamine. Psychopharmacologia (Berlin), 1972, 25, 321-331.

Beckwith, B. E., Sandman, C. A., \& Alexander, W. D. D-amphetamine effects on attention and memory in the albino and hooded rat. Pharmacology, Biochemistry and Behavior, 1974, 2, 557-561.

Braun, J. J. The neocortex and visual placing in rats. Brain Research, 1966, 1, 381-394.

BraUn, J. J. The neocortex and feeding behavior in the rat. Journal of Comparative and Physiological Psychology, 1975, 89, 507-522.

Braun, J. J., Meyer, P. M., \& Meyer, D. R. Sparing of a brightness habit in rats following visual decortication. Journal of Comparative and Physiological Psychology, 1966, 61, 79-82.

CARDo, B. Action de lésions thalamiques et hypothalamiques sur le conditionnement de fuite er al differenciation tonale chez le rat. Journal of Physiology (Paris), 1960, 52, 537-553.

Cicala, G. A., Ulm, R. R., \& Drews, D. R. The effects of chlorpromazine and d-amphetamine on the acquisition and performance of a conditioned escape response in rats. Psychological Record, 1971, 21, 165-169.

Groves, P. M., \& Rebec, G. V. Biochemistry and behavior: Some central actions of amphetamine and antipsychotic drugs. Annual Review of Psychology, 1976, 27, 91-127.

Hearst, E., \& Whalen, R. E. Facilitating effects of d-amphetamine upon discrimination performance. Journal of Comparative and Physiological Psychology, 1963, 56, 124-128.

IVERSEN, S. D., \& IVERSEN, L. L. Behavioral pharmacology. New York: Oxford University Press, 1975.

IzQUIERDo, I. Relations between orienting, pseudoconditioned and conditioned responses in the shuttle-box-A pharmacological analysis by means of LSD and dibenamine. Behavioral Biology, 1975, 15, 192-206.

Jonason, K. R., Lauber, S., Robbins, M. J., Meyer, P. M., \& MEYer, D. R. The effects of dl-amphetamine upon discrimination behaviors in rats with cortical lesions. Journal of Comparative and Physiological Psychology, 1970, 73, 47-55.

KRIECKhaus, E. E. Decrements in avoidance behavior following mammilothalamic tractotomy in rats and subsequent recovery with d-amphetamine. Journal of Comparative and Physiological Psychology, 1965, 60, 31-35.

Krieckhaus, E. E., Miller, N. E., \& Zimmerman, P. Reduction of freezing behavior and improvement of shock avoidance by d-amphetamine. Journal of Comparative and Physiological Psychology, 1965, 60, 36-40.

LAUBer, S. M. Brain histology for neuropsychologists. Psychonomic Monograph Supplements, 1970, 3, 95-102. 
LEITH, N. J., \& BARRETt, R. J. Effects of hippocampal microinjections of d-amphetamine and scopolamine on active avoidance behavior in rats. Journal of Comparative and Physiological Psychology, 1975, 88, 285-299.

MACHT, M. B. Effects of d-amphetamine on hemidecorticate, decorticate, and decerebrate cats. American Journal of Physiology, 1950, 163, 731-732.

Maling, H. M., \& Acheson, G. H. Righting and other postural activity in low decerebrate cats after d-amphetamine. Journal of Neurophysiology, 1946, 9, 379-386.

Meyer, D. R. Access to engrams. American Psychologist, 1972, 27, 124-133.

MeYer, D. R., \& BEATtie, M. S. Some properties of substrates of memory. In L. H. Miller, C. A. Sandman, \& A. J. Kastin (Eds.), Neuropeptide influences of the brain and behavior. New York: Raven Press, 1977.

MeYer, P. M., Horel, J. A., \& MeYer, D. R. Effects of dl-amphetamine upon placing responses in neodecorticate cats.
Journal of Comparative and Physiological Psychology, 1963, 56, 402-404.

MeYer, P. M., Johnson, D., \& VAughn, D. The consequences of septal and neocortical ablations upon learning a two-way avoidance response. Brain Research, 1970, 22, 113-120.

MeYer, P. M., \& MeYer, D. R. In R. D. Myer (Ed.), Methods in psychobiology (Vol. 1). New York: Academic Press, 1971.

RECH, R. H. Amphetamine effects on poor performance of rats in a shuttle-box. Psychopharmacologia (Berlin), 1966, 9, 110-117.

Ritchie, G. D., MeYer, P. M., \& Meyer, D. R. Residual spatial vision of cats with lesions of the visual cortex. Experimental Neurology, 1976, 53, 227-253.

(Received for publication April 21, 1978; revision accepted June 20, 1978.) 